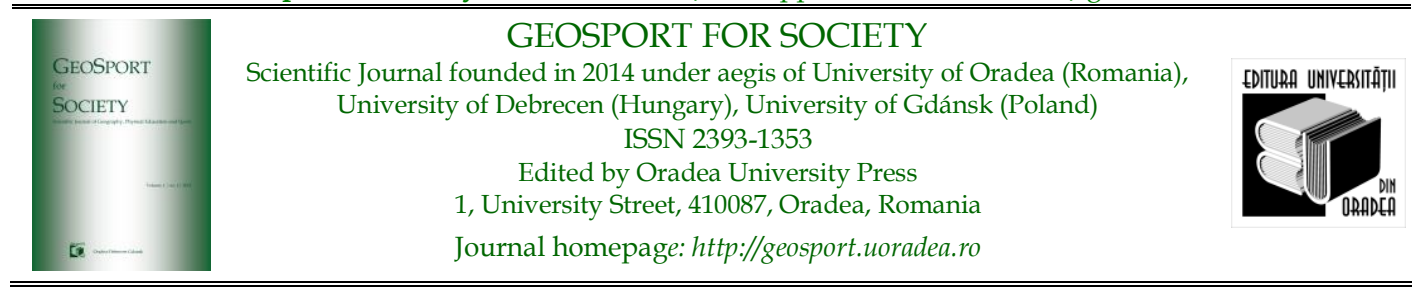

\title{
A Systematic Review of the Impact of COVID-19 on Global Sporting Events in 2020: The Tokyo 2020 Summer Olympics
}

\author{
Tinashe CHUCHU ${ }^{*}$, Eugine Tafadzwa MAZIRIRI ${ }^{2}$, Tarisai Fritz RUKUNI ${ }^{2}$
}

1. University of the Witwatersrand, School of Business Sciences, Marketing Division, 1 Jan Smuts Ave, Braamfontein, cod 2050, Johannesburg, Gauteng, e-mail: tinashe.chuchu@wits.ac.za

2. University of the Free State, Department of Business Management, 205 Nelson Mandela Dr, Park West, cod 9300, Bloemfontein South Africa, e-mails: maziririEt@ufs.ac.za, RukuniTF@ufs.ac.za

* Corresponding author

Citation: Chuchu, T., Maziriri, E.T., \& Rukuni, T.F. (2021). A Systematic Review of the Impact of COVID-19 on Global Sporting Events in 2020: The Tokyo 2020 Summer Olympics. Geosport for Society, $15(2), 82-89$. https://doi.org/10.30892/gss.1502-072

Article history: 05.05.2021; Revised: 20.08.2021; Accepted: 05.09.2021, Available online: 14.09.2021

\begin{abstract}
The Corona virus disease 2019 (COVID-19), like no other pandemic has taken the world by storm, affecting all and any spheres of life. This effect has also impacted global sporting events such as the 2020 Summer Olympics that were scheduled for the 24th of July 2020 to the 9th of July 2020 in Tokyo, Japan. Historically, the Summer Olympics have been cancelled 3 times due to war but the postponement that occurred in 2020 is unprecedented. The socio-economic implications are still yet to be fully explored and realised. The purpose of this research is to therefore examine the impact of COVID-19 on the Tokyo 2020 Summer Olympics. The study will adopt a systematic literature review of material on the COVID-19 pandemic in relation to sporting events and statistical inferences will be conducted based on publicly accessible secondary data sources. Considering that the pandemic is still an ongoing phenomenon the findings and analysis cannot be conclusive, a snapshot based on current data and scientific predictions will be provided on what COVID-19 meant to global sporting events. A broad analysis of the pandemic's impact on sport will be provided despite the focus being on the Tokyo 2020 Summer Olympics. Last, this study serves as a template for further research on COVID-19's impact on sporting events in general, preferably studies conducted post the pandemic for reflection purposes based on more conclusive data.
\end{abstract}

Keywords: COVID-19, 2020 Summer Olympics, Tokyo, Sports, Impact

\section{Introduction}

The COVID-19 pandemic resulted in the postponement and rescheduling of the 2020 Tokyo Olympics for the 23rd of July to $8^{\text {th }}$ of Aug 2021 (James, 2020). Across the globe and to different extents, sporting events were either cancelled or postponed due to the COVID-19 pandemic (James, 2020). The devastating impact of 
Coronavirus on socio-economic activities including sporting events is beyond imagination (Kyung-Hoon, 2020). Coronavirus, a virus that causes a respiratory disease known as COVID-19 began at a wet animal market in the industrial City of Wuhan within the Hubei province in China (Craven et al., 2020). The World Health Organisation (WHO) declared Coronavirus a world pandemic on 30 January 2020 resulting in a chain of events (i.e. social distancing, quarantining, national lockdown) to save lives (Nicola et al., 2020). By 19 June 2020, Coronavirus infections had risen to 8629294 with 457609 deaths across the world (Worldometer, 2020).

As human lives took precedence, the 2020 Summer Olympics were postponed by a year to start from 23 July to 8 August 2021 (Binner, 2020). After Tokyo won the bid to host the 2020 Summer Olympics on 7 September 2013 at the $125^{\text {th }}$ International Olympics Committee (IOC) session in Buenos Aires, megaprojects costing multi-million dollars were triggered in preparation of the world event (Gibson, 2013). However, the postponement of the 2020 Summer Olympics to 2021 due to the outbreak of COVID-19 came at a time when preparation projects were at an advanced stage (Thomas, 2020).

The excruciating decision to postpone the 2020 Summer Olympics has farreaching consequences for individuals and companies involved. Thomas (2020) points out that athletes across the world are living with a feeling of uncertainty ever since the outbreak of COVID-19. United Nations (2020) reports that the closure of sporting facilities (i.e. Olympic training centre in Colorado) to stop the spread of COVID-19 has disrupted the training schedule of Olympics athletes across the world. Social distancing prohibits the opportunity for athletes to train in groups diminishing the opportunity for motivation and support among themselves (Genesis Fitness, 2016). As already mentioned, the Tokyo 2020 Summer Olympics had presented business opportunities for companies and many had spent multi-million dollars to partner with the IOC (Thomas, 2020). The broadcast payments of the Summer Olympics are valued at approximately 169 million dollars (The Sunday Morning Herald, 2020). Venues had been secured and some had been built in advance to accommodate athletes, spectators, and officials across the world (Thomas, 2020; Chappell, 2020). Thomas (2020) also reports that television schedules for the 2020 Summer Olympics had been set and cleared. With billions of dollars at stake, no insurance company is willing to recoup the cost (Thomas, 2020). The following section explores paper's review of literature and supporting theory.

\section{Literature Review and Theory Emergency Management Theory}

Emergency management is a field of study in operations and investigation. An immense transformation has been occurring in emergency management (McEntire, 2005). In emergency management, researchers have been fascinated in accidents, crises, emergencies, disasters, catastrophes, and calamities over the years (McEntire, 2005). Emergency responders operate in an increasingly volatile and uncertain environment (Elbanna et al., 2019; McEntire, 2004; McGuire and Silvia, 2010; Pangarkar, 2016). They rely on intense communication and planning and structured procedures that are closely and professionally regulated (Elbanna et al., 2019). They 
work under varoius types of pressures such as time, uncertainty and unexpected developments of situations, unfolding effects and heavy political and societal examination (Elbanna et al., 2019). Emergency management involves theoretical contributions from the sciences, manufacturing, and the social sciences (Drabek, 2005). The review of the emergency management theory was deemed necessary as the present study was focused on how a global pandemic such as the COVID-19 impacted international events that included the Tokyo 2020 Summer Olympics.

Table 1. Key terms in the Emergency Management Theory Source: Adapted from (Elbanna et al., 2019)

\begin{tabular}{|l|l|}
\hline $\begin{array}{l}\text { Business } \\
\text { Continuity }\end{array}$ & $\begin{array}{l}\text { This is the ability of an organisation to continue providing of } \\
\text { products or services at acceptable predefined levels following a } \\
\text { disruptive occurrence. This could mean a sporting event such as the } \\
\text { Olympics continuing under difficult circumstances. }\end{array}$ \\
\hline Disaster & $\begin{array}{l}\text { A catastrophic disruption of the functioning of a community } \\
\text { concerning extensive human, material, economic or environmental } \\
\text { losses, which hinder that community's ability to cope. }\end{array}$ \\
\hline $\begin{array}{l}\text { Emergency Management } \\
\text { management) }\end{array}$ & $\begin{array}{l}\text { The structuring and allocation of resources and responsibilities for } \\
\text { addressing all aspects of emergencies, specifically in terms of } \\
\text { preparedness, response and initial recovery steps. }\end{array}$ \\
\hline Resilience & $\begin{array}{l}\text { The ability of a system, community or society exposed to dangers to } \\
\text { effectively resist, absorb, accommodate to and pull through from the } \\
\text { effects of the risks faced. }\end{array}$ \\
\hline
\end{tabular}

Decade for Natural Disaster Reduction (IDNDR), reflecting the growing interest in the evolving field of emergency management and planning. It is natural that emergency management should take on a higher level of prominence as the world's level of connectivity increases (Elbanna et al., 2019). The focus on emergency management received an added impetus through the events of 9/11 and these events were a catalyst for change, accelerating interest in emergency management (Elbanna et al., 2019; McEntire, 2004).

\section{The Impact of COVID-19 of the Global Economy}

The COVID-19 pandemic has activated the harshest and deepest contraction of GDP (Gross Domestic Product) in the existence of capitalism as globalisation has digressed (Siddiqui, 2020). International supply chains, which were once the pillars of organised production and the foundations of trade, have failed giving rise to a national economy approach (Siddiqui, 2020). Furthermore, overseas travel and tourism have almost closed entirely (Siddiqui, 2020). In 2019, anxiety emerged over the impact of a US-China trade war, the United States presidential elections, the United Kingdom's exit from the European Union and on the global economy (Ozili and Arun, 2020). Looking at the above mentioned causes for potential anxiety, the International Monetary Fund had anticipated moderate global growth of $3.4 \%$. (Ozili and Arun, 2020). However, COVID-19 - the disease caused by SARS-CoV-2, a novel strain of coronavirus from the SARS species - altered the outlook unpredictably (Ozili and Arun, 2020). Due to fear and insecurity, and to rational assessment that company profits will potentially be lower due to the effects of the 
COVID-19 pandemic, global stock markets lost about $\$ 6$ trillion United States dollars in wealth in one week from the 24th to 28th of February 2020 (Ozili and Arun, 2020). Labour force performance was significantly impacted by the COVID-19 pandemic (Rukuni et al., 2020). The financial fragility of many business organisations was exposed by the COVID-19 pandemic with the median firm with monthly expenses exceeding $\$ 10,000$ United States dollars having only cash in hand to last two weeks (Bartik et al., 2020).

\section{The Impact of the COVID-19 on Sport}

Evans et al. (2020) investigated the impact of sport in the COVID-19 era and suggested that this was an extraordinary time. Furthermore, Evans et al. (2020) acknowledged that, despite the influx of information on the pandemic, the future remained uncertain and this included the future of sport. The COVID-19 pandemic that spread across the world rapidly in a few months resulting in a significant impact on public health, society, and the global economy in general, wreaking havoc to the sporting calendar (Gough, 2019). Sports leagues and federations across the world addressed the COVID-19 pandemic by suspending seasons and stopping activity, for example the cancellation of Wimbledon, tennis' oldest tournament (James, 2020). It has been suggested that in the future, sport will have to be reviewed; this includes establishing who really needs sport, what format changes will be taken and how will these changes affect the professional sports personalities and the fans? (Evans et al., 2020).

It has already been established that the global shut-down or postponement of professional sport at the elite levels is based on the understanding that such 'mass gatherings' significantly exacerbate the dangers of the spread of the virus due to the widespread networks they are based upon (Evans et al., 2020; Widdop et al., 2020). Some sources, Bremmer (2020) and Evans et al. (2020) have explored the closure of globalisation, citing the collective effects of the virus, nationalist and populist agendas in politics and environmental concerns. Sport in the face of the COVID-19 pandemic: towards an agenda for research in the sociology of sport.

\section{Research Method and Data}

A qualitative approach, utilising secondary data sources was adopted. This was through published academic sources from popular databases that include Science Direct and popular mainstream media that claim to use scientific sources. For the most current scientific data on the COVID-19 epidemic, the National Institute of Allergy and Infectious Diseases (NIAID), Centers for Disease Control and Prevention (CDC) and the World Health Organisation (WHO) were consulted for relevant trends and statistics. This research was published between 2014 and 2020 which was then examined and systematically presented and discussed. Selected publications were reviewed and critiqued for their suitability, relevance and contribution. In order to obtain the most relevant research key words were entered in search engines mainly "COVID-19", "Olympic Games" and "Sports" during the time of COVID-19". Based on the above mentioned research method this study generated its own unique findings and conclusions. 


\section{Ethics Statement}

Prior to conducting the research, an ethical clearance certificate was obtained by the researchers from the authorising institution of higher learning. The protocol number is UFS-HSD2020/0797/1206. All stipulated ethical guidelines were followed accordingly. No conflict of interest arose. The following section explores the findings from the systematic review.

\section{Findings}

Research Theme: Loss of Sport-Related Revenue

One of the most commonly recurring themes that resulted from COVID-19's impact on sport is the wide-spread loss of sport related revenue. Table 2 below presents the loss of revenue in the sporting as a result of COVID-19 as of May 2020.

Table 2. Loss of revenue in the sports industry due to the (COVID-19) pandemic as of Source: Gough (2019)

\begin{tabular}{|c|c|}
\hline & Revenue loss in billion U.S dollars \\
\hline Fan Spending on pro-sports & 3.25 \\
\hline Tourism relation to youth sports & 2.4 \\
\hline National TV Revenue & 2.2 \\
\hline $\begin{array}{c}\text { Wages for ticket takers, beer vendors and } \\
\text { other stadium and arena employees }\end{array}$ & 0.37 \\
\hline
\end{tabular}

The following section discusses the implications of the findings and the study's contribution thereafter.

\section{Implications and Recommendations}

The implications of the COVID-19 pandemic are universal. Every aspect of life as it is known was affected. The global economy took massive set-backs. In terms of the pandemic's impact on the 2020 Tokyo Summer Olympics a significant amount of investment was lost; this refers to money that was ploughed-in to develop critical infrastructure as well as funds allocated to support the event during the activities. The first implication is that alternative funding sources are to be secured in the event that the event is hosted in 2021 as proposed. The other implication is that the event organisers would have to prioritise saving funds and potentially scale down their original plans. As it stands, sporting events like any other set-up that brings together large masses of people will have to change due to the impact of the COVID19 pandemic. This implies that the World Health Organisation guidelines aimed at preventing the spread of the virus will have to be implemented for the Olympic Games to be successfully hosted. This therefore means that the Olympic Games would potentially become more expensive than initially budget for because of extra hygiene measures that might be imposed. Logistically there are also concerns, for example; Olympic Games organisers will have to answer the following questions:

- Will the stadiums be operating at "full audience capacity"?

- Will the stadiums be fully fumigated and sanitised prior to each day of games?

- Will it be possible to effectively screen all the audience in attendance for COVID-19? 
- Even if COVID-19 is not detected immediately on either the athletes or fans, symptoms can still show after 2 weeks, what will happen if these symptoms appear?

- It is assumed that in 2021 the outbreak will be over, what if opening-up Japan's border for the Olympics will lead to a spike in infections?

- If there is an outbreak of COVID-19 cases in Japan, specifically Tokyo, will the nation be able to manage it?

The questions above would potentially arise as it should be expected. The following sections explore the potential contribution to be made by the present research followed by its conclusion.

\section{Contribution}

The potential contribution of this research is to provide an analysis of COVID19's impact on global sport with specific attention to the 2020 Tokyo Summer Olympics. This was done through a systematic review that could also be used in comparison with prior research on Olympics and sporting events in general that had to be cancelled or postponed. This research uniquely utilised theories that could aid in explaining the impact of such a pandemic on sport. As for practitioners, specifically organisers of massive sporting events such as the Olympics they serve to benefit from recommendations that emerged from the review. Academics and researchers alike will now understand the proposed frameworks and theories in relation to major sporting events being cancelled due to a global health pandemic. Research on COVID-19 is relatively limited considering that it is a new pandemic that is still being comprehended. This therefore suggests that significant contributions in research are still being developed making this paper one of the first attempts to conduct a systematic review of the pandemic's impact on the 2020 Tokyo Summer Olympics.

\section{Conclusion}

The purpose of this research is to therefore examine the impact of the COVID19 on the Tokyo 2020 Summer Olympics. Based on the publicly accessible information regarding the pandemic's impact on sports is undeniably significant. However, its full impact is yet to be fully realised in the years to come as this is still an active crisis and it is unknown when it will end.

\section{Suggestions for Further Research}

The present research like any other research was not immune to its own set of limitations. First, the study relied solely on publicly available information. This could have led to critical details being omitted from the review and comprising the ability to fully examine the COVID-19 impact on the 2020 Tokyo Summer Olympics. It would therefore be recommended that future research be conducted through support of large medical bodies or associations that have the legal and moral authority to research such details. For instance, it could be inferred that certain details pertaining to the COVID-19 cannot be released, such as details that could cause political, economic and social crises. Having such details classified as confidential 
by governments or international bodies restricts the full extent to which any research can provide a clear, unbiased and complete picture of the pandemic's impact.

This research was a systematic review which attempted to provide a fair examination of the pandemic as much as possible. However, this was and can never be exhaustive. Further, research could be more comprehensive. For example, conducting an empirical study involving human subjects that are knowledgeable about Olympic Games and requesting them to complete a comprehensive questionnaire allowing the researchers to have primary data. The advantage of having primary data is that the data would have been collected through specific questions related to the problem under investigation.

Aside from conducting a quantitative study on the COVID-19's impact on the 2020 Tokyo Summer Olympics, qualitative in-depth interviews can be conducted with key players or experts on such events. This could be local Olympic Games Organising Committee officials from the author(s) country as this does not necessarily have to be an official from the host nation's official Olympic Games Organising Committee. Last, due to the global COVID-19 guidelines that include, social distancing, self-isolation as well as most nations imposing lockdowns, it is believed that post-COVID-19 research can be more informative, refined and potential build of the idea that this research was founded upon.

\section{References}

Bartik, A. W., Bertrand, M., Cullen, Z., Glaeser, E. L., Luca, M., \& Stanton, C. (2020). The impact of COVID19 on small business outcomes and expectations. Proceedings of the National Academy of Sciences, 117(30), 17656-17666.

Binner, A. (2020). New Tokyo 2020 Olympic dates will be 23 July to 08 August 2021.

Chappell, B. (2020). IOC Will Devote $\$ 800$ Million To Postponed Tokyo Olympics, COVID-19 Costs. Retrieved from: https://www.npr.org/sections/coronavirus-liveupdates/2020/05/15/857080028/ioc-will-devote-800-million-to-postponed-tokyo-olympicscovid-19-costs, accessed: 19/06/2020.

Craven, M., Liu, L., Mysore, M., \& Wilson, M. (2020). COVID-19: Implications for business. McKinsey \& Company, 1-8.

Drabek, T. E. (2005). Theories relevant to emergency management versus a theory of emergency management. Journal of Emergency Management, 3(4), 49-54.

Genesis Fitness. (2016). Five benefits of group training. [Online] Available on: https://www.genesisfitness.com.au/blog/5-benefits-grouptraining\#: :text=Combining\%20group\%20training\%20sessions\%20into,weight\%20or\%20tone\% 20your\%20body.\&text=Just\%20like\%20personal\%20training\%2C\%20group,100\%25\%20effort $\%$ 20into\%20your\%20workout, accessed: 19/06/2020.

Gibson, O. (2013). Tokyo wins the race to host 2020 Olympic Games: Japanese capital beats Madrid and Istanbul after prime minister Shinzo Abe flew in to reassure voters over Fukushima. Retrieved from https://www.theguardian.com/sport/2013/sep/07/tokyo-host-2020-olympic-games, accessed $27 / 04 / 2021$.

Elbanna, A., Bunker, D., Levine, L., \& Sleigh, A. (2019). Emergency management in the changing world of social media: Framing the research agenda with the stakeholders through engaged scholarship. International Journal of Information Management, 47, 112-120.

Evans, A. B., Blackwell, J., Dolan, P., Fahlén, J., Hoekman, R., Lenneis, V., McNarry, G., Farazmand, A. (2014). Crisis and emergency management: Theory and practice. Crisis and emergency management. Routledge 25-34. 
Gough, C. (2019). Coronavirus (COVID-19) disease pandemic effect on the sports industry - Statistics \& Facts. Statista Retrieved from:https://www.statista.com/topics/6098/impact-of-the-coronaviruson-sport, accessed on: 03/07/2020.

James, W. (2020). Looking for a Full Sports Calendar? Try Nicaragua. The New York Times. Retrieved from: https://www.nytimes.com/2020/04/14/sports/coronavirus-nicaragua-sports-events.html, accessed: 03/07/2020.

Kyung-Hoon, K. (2020). Major sports events around the world that are in the process of re-starting or which have been rescheduled due to the Covid-19 pandemic. Reuters. Retrieved from: https://mobile.reuters.com/article/amp/idUSKBN22X2LL, accessed: 18/06 /2020.

McEntire, D. A. (2004). The status of emergency management theory: Issues, barriers, and recommendations for improved scholarship. University of North Texas. Department of Public Administration. Emergency Administration and Planning.

McEntire, D. A. (2005). Emergency management theory: Issues, barriers, and recommendations for improvement. Journal of Emergency Management, 3(3), 44-54.

McGuire, M., \& Silvia, C. (2010). The effect of problem severity, managerial and organizational capacity, and agency structure on intergovernmental collaboration: Evidence from local emergency management. Public Administration Review, 70, 279-288.

Nicola, M., Alsafi, Z., Sohrabi, C., Kerwan, A., Al-Jabir, A., Iosifidis, C., Agha, M. \& Aghaf, R. (2020). The socio-economic implications of the coronavirus pandemic (COVID-19): A review. International Journal of Surgery, 78, 185-193.

Olympic Channel. Retrieved from: https://www.olympicchannel.com/en/stories/news/amp/newtokyo-2020-olympics-2021-dates-revealed, accessed: 19/06/2020.

Ozili, P. K., \& Arun, T. (2020). Spillover of COVID-19: impact on the Global Economy. Available at SSRN 3562570.

Pangarkar, N. (2016). A framework for effective crisis response. Journal of Organizational Change Management, 29, 464-483.

Rukuni, T. F., Maziriri, E. T., \& Chuchu, T. (2020). Data on occupational health and safety strategies influencing the reduction of coronavirus in South Africa. Data in brief, 32, (October), 1-7. https://doi.org/10.1016/j.dib.2020.106300

Siddiqui, K. (2020). The Impact of Covid-19 on the Global Economy. The World Financial Review, MayJune, 25-31.

The Sunday Morning Herald. (2020). The eye-watering cost of Tokyo 2020 Olympics postponement. Retrieved from: https://www.smh.com.au/sport/the-eye-watering-cost-of-tokyo-2020-olympicspostponement-20200515-p54t8n.html, accessed: 19/06/2020.

Thomas, L. (2020). Covid-19 is a threat to the 2020 games. The I.O.C is a threat to the Olympic project. New Yorker. Retrieved from: https://www.newyorker.com/sports/sporting-scene/covid-19-is-athreat-to-the-2020-games-the-ioc-is-a-threat-to-the-olympic-project/amp, accessed: 19/06/2020.

United Nations (2020). The impact of COVID-19 on sport, physical activity and well-being and its effects on social development. United Nations Retrieved from: https://www.un.org/development/desa/dspd/2020/05/covid-19-sport, accessed: 19/06/2020.

Worldometer (2020). COVID-19 coronavirus outbreak. Retrieved from: https://www.worldometers.info/coronavirus, accessed: 19/06/2020. 